\title{
Metodologias de representação da informação imagética
}

\section{Methods of imagetic information representation}

Giovana Deliberali MAIMONE'

Maria de Fátima Moreira TÁLAMO²

\section{RESUMO}

O presente trabalho tem a finalidade de evidenciar algumas das metodologias de representação da informação imagética, revisitando a literatura da área e propondo um modelo de metodologia adaptada a museus brasileiros. Elabora-se uma proposta de metodologia de representação da informação imagética com base nas características de tratamento informacional, a fim de realizar adaptação museológica. Apresentam-se, por fim, as planilhas que evidenciam essa metodologia.

Palavras-chave: metodologias; imagens; representação da informação imagética.

\begin{abstract}
The aim of this paper is to highlight some of the methods of imagetic information representation, reviewing the literature of the area and proposing a model of methodology adapted to Brazilian museums. An elaboration of a methodology of imagetic information representation is developed based on Brazilian characteristics of information treatment in order to adapt it to museums. Finally, spreadsheets that show this methodology are presented.
\end{abstract}

Keywords: methodologies; images; imagetic information representation.

\section{INTRODUÇÃO}

A representação documentária da informação imagética em relação à representação de outros tipos de materiais como livros, artigos de revistas, jornais, etc. mostra-se atrasada devido às restritas e incipientes pesquisas nesta área de conhecimento. Neste sentido
- objetivo deste artigo é mostrar algumas destas iniciativas e revisitar a literatura da área, propondo um modelo de metodologia que se adapte aos museus brasileiros. Esta proposta conta com planilhas que evidenciam a necessidades de representar informações tanto de cunho descritivo quanto temático para busca e recuperação de informações de imagens.

1 Doutoranda em Ciência da Informação, Escola de Comunicação e Artes, Universidade de São Paulo. São Paulo, SP, Brasil. Correspondência para/Correspondence to: G.D. MAIMONE. E-mail: <bci.gdm@gmail.com>.

2 Docente do Programa de Pós-Graduação em Ciência da Informação, Escola de Comunicação e Artes, Universidade de São Paulo. São Paulo, SP, Brasil. E-mail: <mfmgtala@usp.br>.

Recebido em 12/2/2009 e aceito para publicação em 30/9/2009. 


\section{METODOLOGIA}

Metodologia, segundo Cunha e Cavalcanti (2008, p. 248), é a "parte da lógica que estuda a aplicação dos princípios do raciocínio à pesquisa científica, filosofia e técnica". Apesar dessa definição, este trabalho concebe metodologia dentro do patamar científico como procedimentos adotados para a resolução de determinado problema, ou seja, "um conjunto de métodos, regras e postulados utilizados em determinada disciplina e sua aplicação" (Ferreira, 2000, p. 460). Sob essa perspectiva, as formas (procedimentos) adotadas para indexação de imagens configuram-se numa metodologia, já que procuram determinar "modos" de execução de tarefas, pressupondo a "orientação" por métodos de raciocínio lógico.

Em pesquisas anteriores, foi possível identificar no cenário nacional três metodologias de representação que, embora não tratem especificamente de pinturas, utilizam a indexação para representar o conteúdo dos materiais imagéticos. A metodologia estabelecida por (Smit, 1987) propõe seis parâmetros para a representação de imagens. Segundo a autora

[...] a análise de imagens não precisa chegar a uma especificidade muito grande, mantendo, portanto, uma amplitude suficiente para que, a qualquer pergunta, se possa selecionar ao redor de 30 imagens que respondam à pergunta (Smit, 1987, p. 107).

A descrição, portanto, deve responder às seguintes perguntas:

- Quem (seres vivos)

- Onde (ambiente/espaço) - local

- Quando (tempo)

- $\bigcirc$ que (ação)

- Como (técnica)

Se essas perguntas forem respondidas, pode-se supor que nenhum detalhe realmente importante tenha sido esquecido. Há também a metodologia utilizada pela Biblioteca Nacional (Alves; Valerio, 1998) para fotografias (materiais ilustrativos), as quais revelam um aspecto histórico relevante. Essa metodologia consiste em pesquisar o conteúdo geral da imagem, visto que ela dificilmente traz alguma informação escrita, e quando traz, nem sempre é absolutamente correta. Pergunta-se então:

- Quem fotografou?

- Quando?

- Onde?

- Que e/ou quem foi fotografado?

Ainda em se tratando de materiais fotográficos, identificou-se o trabalho de Miriam Manini (2002), cuja metodologia de tratamento informacional pode ser resumida no quadro abaixo:

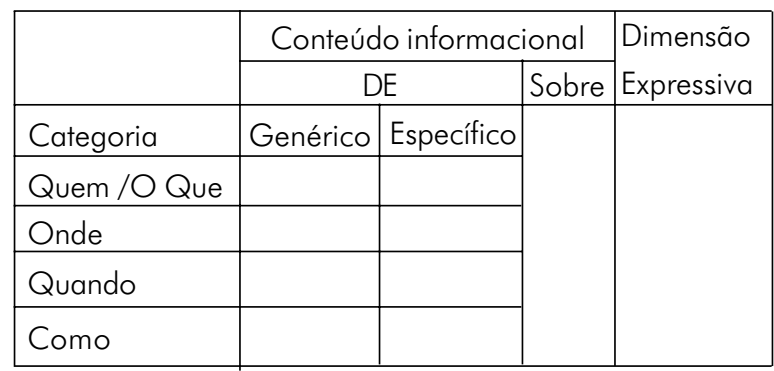

Figura 1. Metodologia de tratamento de imagens. Fonte: (MANINI, 2002, p. 110)

A metodologia sugerida por Manini (2002) apresenta a Dimensão Expressiva da Imagem, referente ao tipo de material de que é composta a obra. E identifica também, através do DE e do SOBRE, as linhas que separam aspectos visíveis (concretos) dos subjetivos (abstratos). O DE pode ser classificado mais com termos "concretos"; já o SOBRE envolve a interpretação do indexador.

A atribuição das palavras "genérico" e "específico" às perguntas indexadoras (quem/o que, onde, quando e como) tem a função de distinguir as informações. A primeira diz respeito ao que está sendo tratado essencialmente nos materiais, ou seja, que está enfaticamente explicitado em primeiro plano nas imagens. Já a segunda se diferencia por tratar de informações secundárias, ou seja, que figuram em segundo plano nas imagens.

A fim de que se tenha compreensão mais clara da indexação, é necessário explicar o significado das categorias informacionais (quem/o que, onde, quando e como) utilizadas no quadro. 
Quem/o que = Identificação do "objeto enfocado": seres vivos, artefatos, construções, acidentes naturais, etc.

Onde = Localização da imagem no espaço: espaço geográfico ou espaço da imagem ( $p$. ex.: São Paulo ou interior de danceteria)

Quando = localização da imagem no tempo: tempo cronológico ou momento da imagem ( $p$. ex.: junho de 1997 ou dia de verão).

Como $=$ descrição de atitudes ou detalhes relacionados ao 'objeto enfocado' quando este é um ser vivo (p. ex.: cavalo correndo, criança trajando roupa do século XVIII) (Smit, 1987, p. 103).

Apesar dessas metodologias encontradas em cenário nacional revelarem iniciativas relevantes para a área, em âmbito internacional foi possível encontrar a metodologia de María del Carmen Agustín Lacruz que conta com um volume exaustivo de informações.

\section{Metodologia aplicada por María del Carmen Agustín Lacruz}

A pesquisadora estuda os retratos de Francisco de Goya (pintor e retratista espanhol), detalhando tanto a fase de análise do conteúdo como a fase de representação documentária. Incluem-se também os resumos documentários, os descritores categorizados e normalizados e a compilação das fontes bibliográficas consultadas. A exposição de cada um desses itens é estruturada em cinco etapas sucessivas.

- Em primeiro lugar, apresenta-se a reprodução gráfica de cada retrato a ser tratado.

- Em continuação, efetiva-se a catalogação do retrato, incluindo os dados disponíveis relativos à autoria; denominação habitual (título); data de realização e, se for o caso, datas de retoques; descrição física da natureza do suporte com suas dimensões em centímetros; indicação da cidade e da instituição pública ou privada em que se situa atualmente a obra; os números catalográficos correspondentes aos diferentes inventários artísticos e, se existirem, o conteúdo e a disposição de inscrições textuais gravadas no retrato.

- Posteriormente, é realizado o processo de análise do conteúdo de cada retrato, colocando-se, de forma estratificada em dois níveis respectivos de exaustividade - o indicativo e o informativo, conforme a terminologia habitualmente utilizada para diferenciar os resumos científicos segundo a densidade de informações abordadas - a descrição, a identificação e a interpretação de cada representação icônica. É válido salientar que esses processos de descrição, identificação e interpretação dos conteúdos são agentes incrementadores da análise, visto que aprofundam informações que complementam a "representação" das obras, conforme será visto mais adiante, na descrição de cada item.

- Em seguida, relacionam-se as respectivas representações documentárias do conteúdo: resumos científicos e descritores controlados, organizados em categorias distintas, segundo a natureza de seus termos - onomásticos, cronológicos, topográficos, formais, temáticos referenciais e temáticos não-referenciais, respectivamente.

- Finalmente, compila-se de forma exaustiva a literatura científica que se utilizou para efetivar a análise do conteúdo, organizando-a em uma sequência alfabética.

A título de uma melhor visualização da metodologia, coloca-se a estruturação idealizada por Agustín Lacruz em seu livro Análisis documental de contenido del retrato pictórico: propuesta epistemológica y metodológica aplicada a la obra de Francisco de Goya.

\section{Exposição do retrato}

\section{Catalogação}

Autor: Nome do autor da obra

Título: Título da obra

Data: Data de realização da obra

Descrição física: Descrição física da obra com suas dimensões em centímetros

Localização: Cidade e Instituição em que se situa atualmente a obra

Catalogações: Números catalográficos correspondentes aos diferentes inventários artísticos

Inscrição: Algum registro/gravação encontrado na obra 


\section{Análise do conteúdo}

Segundo Panofsky (1991) apud Manini (2002), existem três níveis para identificar a mensagem e o significado das obras de arte: o pré-iconográfico, que é a descrição de elementos constitutivos da imagem, ou seja, o referente; o iconográfico, que trata da identificação de assuntos específicos e conceitos manifestos, remetendo ao reconhecimento de um significado atribuível ao referente (análise); o iconológico, que diz respeito a valores simbólicos, ou seja, significados somente detectáveis e/ou observáveis cultural, social, filosófica ou ideologicamente (interpretação).

Descrição - Indicativa e informativa

A descrição é a operação documentária que corresponde ao nível de estudo pré-iconográfico.

É, todavia, uma operação analíitica necessária e incontestável para levar a cabo as restantes identificação e interpretação. No caso específico dos retratos pictóricos, o objetivo dessa operação documentária é compilar dados das figuras humanas e objetos representados. Já em relação às pinturas,é importante a descrição da imagem percebida num primeiro momento.

A forma indicativa é mais resumida que a informativa, carregando esta última um nível maior de detalhes.

Identificação - Indicativa e informativa

A identificação é a operação documentária que concerne ao nível de estudo iconográfico, correspondente ao estrato intermediário da análise do conteúdo artístico. Consiste na individualização e personalização dos temas e motivos iconográficos representados por meio de pessoas, figuras, objetos, lugares, acontecimentos e cenas reconhecidas na operação anterior. Em retratos, por se tratar da representação de pessoas, recorre-se sempre a materiais que possam contribuir para a identificação do personagem ali retratado. Em pinturas artísticas, que contam com diversas tipologias de representação (paisagens, retratos, abstrações, etc.), verifica-se a importância de identificar, no caso de retratos, a biografia do personagem. Em outros casos, porém, importa a biografia do autor da obra, reconhecendose o que aquela obra representa no contexto de vida do autor e estabelecendo-se relações com a escola artística seguida e também com pintores contemporâneos que usaram da mesma técnica.

\section{Interpretação}

A interpretação é a operação documentária que se refere ao nível de estudo iconológico, correspondente ao estrato mais profundo da análise do conteúdo artístico. Para levá-la a cabo, o documentalista considera a intencionalidade do artista, o ambiente históricocultural, a função, o alcance e o propósito da obra. Supõe um estágio de abstração, profundidade e complexidade superior à leitura iconográfica, pois intenta apreender a significação profunda da obra artística. No caso dos retratos, a interpretação iconológica está muito relacionada com as distintas tipologias que se desenvolvem dentro do próprio gênero. Assim, por exemplo, os retratos reais de ostentação estão vinculados com a visualização do poder por meio da representação de seus atributos.

A interpretação pode ser entendida como uma junção dos processos anteriores, por intermédio do reconhecimento dos aspectos técnicos da obra codificação/decodificação dos sistemas semióticos e dos códigos artísticos -, já colocados anteriormente neste capítulo.

\section{Representação documentária do conteúdo e elaboração de produtos documentários}

A representação documentária é a fase de expressão da análise realizada anteriormente. Seu objetivo é redigir representações secundárias, produzidas por meio de instrumentos intermediários que facilitam o acesso e a recuperação do conteúdo das manifestações da criatividade humana.

Os produtos documentários estão estreitamente ligados aos níveis de análise, de tal maneira que a aplicação de cada um deles provê uma informação de 
maior qualidade, progressivamente mais estruturada, sintética e controlada, e todas em seu conjunto proporcionam estratégias de acesso temático que se complementam entre si.

\section{Resumo}

O resumo documentário aborda uma informação considerada mais detalhada e articulada que a dos índices de classificação, dos descritores e das palavras-chave e permite ao usuário decidir se interessa consultar a obra entre um conjunto de referências. $\bigcirc$ resumo indicativo congrega elementos pré-iconográficos e objetivos, descrevendo a obra. A parte informativa deve completar aspectos sobre as mensagens implícitas na obra, decifradas por meio da análise iconográfica e iconológica.

Percebe-se que os resumos dos retratos tratados no estudo de Agustín Lacruz (2006) agregam as três fases da análise do conteúdo (Descrição/Identificação/ Interpretação) sintetizando, porém, as partes mais importantes de cada uma delas.

\section{Descritores}

Em representação de documentos, as linguagens documentárias desenvolvem uma tarefa muito importante, pois são estas ferramentas linguísticas que permitem controlar o léxico com o qual se formulam as demandas dentro dos sistemas de informação. Desempenham, assim, uma função primordial nos processos de mediação entre as coleções documentais e os distintos tipos de usuários e tornam possível também o relacionamento entre obras de arte e coleções, assim como a realização de estudos comparativos entre artistas, etapas criativas de um ou vários artistas, escolas, etc.

Os descritores livres podem ser palavras extraídas do resumo ou descritores em linguagem natural. Já os descritores controlados mediante um tesauro são fundamentais para se conseguir uma relação ótima de exaustividade e precisão na hora da busca, eliminando problemas de polissemia, sinonímia e outros inconvenientes derivados.

Abaixo estão os descritores utilizados no estudo espanhol, e alguns exemplos:

Cabe ressaltar que esses descritores, quando controlados, permitem melhor representação e recuperação da informação já que, quando da indexação dessas informações, utilizando-se de ferramentas como linguagens documentárias, torna-se possível a interligação entre os vários modos de se chamar a mesma coisa.

\begin{tabular}{|c|c|}
\hline Onomásticos & $\begin{array}{l}\text { (nome da pessoa retratada ou da obra em si e datas, se necessário, para } \\
\text { identificá-la). Ex.: María Luisa, rainha de Carlos IV, rei da Espanha (1751 - } \\
\text { 1819). }\end{array}$ \\
\hline Cronológicos & (de tempo - ano de realização da obra) Ex.: 1799. \\
\hline Topográficos & $\begin{array}{l}\text { (localização - lugares e territórios retratados nas obras). Ex.: Espaço } \\
\text { exterior. Paisagem. Montanhas. Construções arquitetônicas. }\end{array}$ \\
\hline Formais & $\begin{array}{l}\text { (tipo de técnica empregada). Ex.: Retrato de corpo inteiro. Retrato de perfil. } \\
\text { Retrato psicológico. Obra mestra. }\end{array}$ \\
\hline Temáticos referenciais & $\begin{array}{l}\text { (objetos e processos presentes na obra, ou seja, que se referem ao quadro). } \\
\text { Ex.: Mulher adulta. Rainha da Espanha. Uniforme militar. Chapéu. Cabelos }\end{array}$ \\
\hline Temáticos não referenciais & $\begin{array}{l}\text { (objetos e processos sugeridos ou ilustrados pelo documento, mas não } \\
\text { exatamente expostas no documento). Ex.: Monarquia. Dinastia. Posição social. } \\
\text { Poder militar. Exército espanhol. }\end{array}$ \\
\hline
\end{tabular}

Figura 2. Exemplos de descritores da metodologia Agustín Lacruz.

Fonte: Agustín Lacruz (2006, p. 210). 


\section{Bibliografia}

As referências utilizadas para o tratamento informacional do conteúdo das obras são colocadas em ordem alfabética ao final de cada processo.

\section{ANÁLISE DO CENÁRIO PAULISTA EM MUSEUS DE ARTE - PINTURAS}

Pôde-se verificar, por meio de observações realizadas em instituições museológicas paulistas, que elas, apesar de contemplarem os requisitos descritivos necessários para exposição das obras, não realizam tratamento documentário das imagens, no nível de detalhe especificado pela metodologia de Agustín Lacruz (2006), até porque se infere que aos museus brasileiros competem preocupações com a forma estética da obra, a fim de transmitir ao público visitante melhores condições de contemplação/admiração, tendo caráter apenas referencial as informações contidas nas etiquetas. Outra justificativa advém da falta de financiamento de pesquisa documentária para essas instituições, suprimindo expectativas de avanço para a construção e desenvolvimento dessa etapa.

De acordo com estudos anteriormente realizados, é notório que, em contexto bibliográfico (de acervo bibliográfico), há tanto metodologia quanto linguagens especializadas para representação e recuperação da informação; porém, no que diz respeito ao tratamento das "obras" propriamente ditas, além de não possuírem metodologias, também não gozam de um sistema de indexação que reflita preocupações quanto ao seu conteúdo; conseqüentemente, não poderiam existir terminais de pesquisas se não existem bases de dados para se pesquisar. Esse fato permite deduzir que a inquietação central dessas instituições não diz respeito à transmissão de informação para geração de conhecimentos e sim à exibição das obras esteticamente.

\section{PROPOSTA DE METODOLOGIA ADAPTADA A MUSEUS BRASILEIROS}

A metodologia utilizada Agustín Lacruz (2006) para o estudo de imagens pictóricas parece bastante completa e exaustiva, demonstrando preocupação recorrente com a análise do conteúdo desses materiais.
Porém, por razões sócio-econômicas encontradas em contexto brasileiro (muito diversas do espanhol), julgase mais viável propor uma metodologia menos exaustiva, mas que contemple os elementos fundamentais de informação para que se possa fazer de maneira pragmática e eficiente a representação de imagens visando à geração de conhecimento nos usuários de museus e pinacotecas.

Pelas razões apresentadas, propõe-se a seguinte metodologia para se aplicar às pinturas em contexto brasileiro:

\section{A imagem propriamente dita (digitalização)}

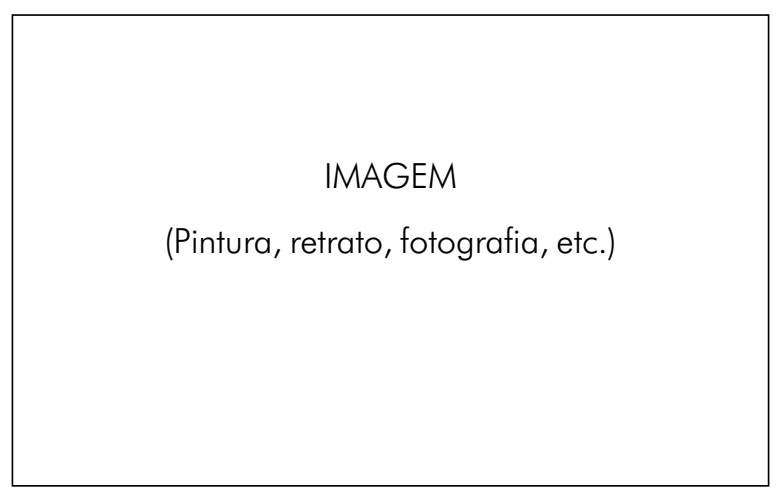

\section{Dados catalográficos}

A representação descritiva, segundo Ribeiro (2003, p. 8-5), dispõe os materiais pictóricos dentro do item materiais gráficos, os quais

[...] significam todos os tipos de materiais em duas dimensões, opacos como obras de arte, quadros de pintura, gravuras, etc. ou destinados a serem vistos ou projetados sem movimento, por meio de um instrumento óptico.

Nesse sentido, as normas para descrição bibliográfica dos documentos ressaltam a importância da descrição física dos materiais gráficos, argumentando facilidade na sua identificação. Para a presente proposta foi preciso realizar algumas adaptações que se mostraram necessárias para a adequada descrição desses materiais, no intuito de não avolumar a catalogação com dados supérfluos e também de não sintetizar demais a ponto de perder informações importantes. 
AUTOR DA OBRA: nome por extenso.

LOCAL E DATA DE NASCIMENTO E DE MORTE DO AUTOR: nome da cidade e país de nascimento por extenso, ano - nome da cidade e país de morte por extenso, ano. A inclusão desse campo permite relacionar o artista com outros que viveram na mesma época. Para não exceder o espaço da planilha serão colocados os símbolos (*) para nascimento e (+) para morte.

TÍTULO DA OBRA: nome por extenso.

ANO DE EXECUÇÃO DA OBRA: ano com quatro dígitos.

DGM (DESIGNAÇÃO GERAL DO MATERIAL): tipo de suporte material em que é feita a obra. A lista britânica de suportes sugere a utilização do termo "material gráfico" para todos os tipos de materiais. Já na lista dos EUA, Canadá e Austrália, os termos variam de acordo com o tipo de material, utilizando o termo genérico "ilustração" para designar materiais não encontrados na lista (Ribeiro, 2003). Sugere-se a utilização da lista dos EUA, Canadá e Austrália, pois a atribuição de termos é controlada, valendo-se de lista de termos pré-estabelecida. Essa lista é composta por:

\begin{tabular}{|c|}
\hline cartão-relâmpago \\
\hline desenho técnico \\
\hline diafilme \\
\hline diapositivo \\
\hline ilustração \\
\hline original de arte \\
\hline reprodução de arte \\
\hline transparência \\
\hline
\end{tabular}

Para a coleção tratada, supõe-se que o termo "originais de arte" seria vastamente utilizado; sendo assim, acrescenta-se ao termo o tipo de material utilizado.

\begin{tabular}{|l|l|}
\hline \multirow{4}{*}{ Original de arte } & Óleo sobre tela \\
\cline { 2 - 2 } & Nanquim sobre tela \\
\cline { 2 - 2 } & Grafite sobre papel \\
\cline { 2 - 2 } & Giz sobre papel \\
\hline
\end{tabular}

DIMENSÕES DA OBRA: altura x largura em centímetros, excluindo a moldura.

LOCALIZAÇÃO-SEDE DA OBRA: país, nome da instituição. É importante ressaltar a sede original da obra, pois pode estar em exposição em outro local.

INSCRIÇÕES CONTIDAS NA OBRA: descrever essas inscrições. Este campo pode servir como uma das características para provar a originalidade da obra, por isso a atenção em transcrevê-lo. Neste trabalho não serão abordados tais dados, pois não se teve acesso a essas informações, iá que se restringem ao pessoal que trabalha diretamente com as obras.

PROCEDÊNCIA: modo de aquisição da obra. Dependendo da obra e da instituição, essa informação é explicitada ou não. Se a resposta for positiva, é importante seguir a transcrição de acordo com o registro da Instituição.

\section{Análise do Conteúdo}

São redações de textos que englobam as categorias abaixo:

a) DESCRIÇÃO: descrever objetivamente o que está representado na pintura, observando suas características particulares.

b) IDENTIFICAÇÃO: identificar o tema e os motivos artísticos retratados na pintura, atentando para a importância da biografia de personagens retratados e também da biografia do autor da obra, reconhecendo sua significação para o contexto de vida do artista e estabelecendo relações com a escola artística, assim como com pintores contemporâneos que usaram da mesma técnica, ou que podem se relacionar de alguma maneira com a obra.

c) INTERPRETAÇÃO: interpretar os significados mais profundos que advêm das análises anteriores, como os códigos artísticos e a contextualização peculiar de cada obra, considerando a intencionalidade do artista, o ambiente histórico-cultural, a sociedade, o propósito da obra, etc.

Adaptando-se esta proposta à de Agustín Lacruz (2006) há necessidade de restringi-la ao nível indicativo de exaustividade para as três fases da análise do 
conteúdo, observando que, apesar de delimitarem as informações para um contexto mais reduzido, contemplam informações fundamentais para representação pragmática e eficiente das pinturas, considerando o pouco investimento em cultura no Brasil (no caso, de recursos humanos - documentalistas para tratamento do conteúdo de imagens). Assim, torna-se necessário relevar primeiramente o nível mais básico de representação, considerando o tempo gasto em recuperações exaustivas, porém ideais.

\section{Representação do Conteúdo: Resumo E Descritores}

A representação do conteúdo é considerada como a fase que resulta em produtos documentários, ou seja, reflete a parte a que os usuários têm acesso. Nesse sentido, há necessidade de enfatizar que este é o momento crucial para a recuperação de informações e, sendo assim, torna-se preciso o ajustamento das categorias de informação (descritores) que se adaptem melhor ao contexto nacional e à síntese das análises feitas na etapa anterior (resumos). É conveniente ressaltar que as categorias já colocadas na ficha catalográfica necessitam reaparecer no estudo de descritores, pois diferem em relação à sua funcionalidade. Na ficha tem-se o modo de apresentação dessas informações, e nos descritores a definição de regras de como os termos devem ser indexados e buscados.

\section{Resumo:}

Texto-síntese das três fases da análise do conteúdo descrição, identificação e interpretação.

Descritores:

São os pontos de acesso pelos quais se faz a recuperação das obras desejadas. Neste quesito, há necessidade de complementar a metodologia de Agustín Lacruz (2006), acrescentando alguns descritores e eliminando outros. Acrescentando, pois há possibilidade de estabelecer outras categorias de descritores que ampliariam o escopo de busca e recuperação por parte do usuário, eliminando algumas categorias que na realidade não especificam o tipo de informação desejada. É o caso de "descritores onomásticos", que podem ser qualquer informação relacionada a nomes (nome do autor, nome dos personagens, nome do local em que foi realizada a obra, etc.), ou seja, o modo de intitular as categorias de descritores é inadequado. Nesse sentido, justifica- se o emprego de outros termos em virtude dos estipulados por aquele estudo.

\section{Tipos de descritores:}

ONOMÁSTICO X AUTORIA: como já mencionado acima, o termo onomástico é muito abrangente, não especificando a tipologia de informação requerida. Apesar do estudo de María del Carmen Agustín Lacruz descrever a informação desejada, pensa-se ser necessário que a categoria reflita diretamente a informação a ser colocada, para não causar "transtornos", que podem acarretar "perda de tempo", "mal-entendidos" e "duplicação de trabalho".

TÍTULO: descritor incluído, pois há possibilidade de o usuário procurar a informação pelo nome da obra.

CRONOLÓGICOS e CRONOLOGIA: época de realização da obra, não correspondendo somente ao ano específico de sua realização, ampliando o leque de possibilidades de recuperação, se, por exemplo, o usuário necessitar de alguns pintores do século XVII.

TOPOGRÁFICOS: categoria descartada pela possibilidade de ser englobada no item "temáticos descritivos".

FORMAIS: categoria descartada, pois corresponde à designação geral do material, ou seja, já foi incluída em dados catalográficos.

NATUREZA OU FORMA ARTÍSTICA: descritor incluído, pois há possibilidade de o usuário procurar a informação pelo nome da escola (movimento) artística desejada. Ex.: Expressionismo.

\section{TEMÁTICOS REFERENCIAIS X TEMÁTICOS}

DESCRITIVOS: o segundo título reflete com mais clareza a tarefa a ser realizada, ou seja, descrição do que está presente na obra, pois até por redundância fazem referência a ela. Nesta categoria podem ser incluídos os descritores topográficos, pois o usuário pode buscar pelo lugar retratado na obra. Ex.: Imagem de cidade. São Paulo. Prédios.

TEMÁTICOS INTERPRETATIVOS ao invés de TEMÁTICOS NÃO REFERENCIAIS, pois tornam 
transparente o trabalho do indexador que fará a interpretação do que está presente na obra, com base em conhecimentos especializados e na sociedade. Ex.: Evolução das cidades. Urbanização. Modernidade.

\section{Padronização dos descritores:}

Toda estrutura de tratamento informacional montada e exposta por meio da planilha a seguir e as metodologias utilizadas para sua elaboração têm como recurso fundamental o uso de linguagens, prioritariamente no que diz respeito aos descritores. Nesse sentido, como aponta Buckland (2006, p. 4), "Toda descrição é uma atividade de linguagem", e "o uso de vocabulários padrão possui a vantagem da consistência e auxilia na compreensão". A partir desse contexto, julga-se bastante pertinente a elaboração de estruturas de linguagens que possibilitem a recuperação de informações. Nesse sentido, intentou-se estabelecer para os itens AUTORIA, TíTULO e CRONOLOGIA listas de palavras que auxiliem os usuários a efetuar buscas orientadas pautadas em tais instrumentos.

\section{- Listas de descritores: Autoria, Título e Crono- logia}

\section{LISTA DE AUTORIA}

Busca pelo sobrenome do autor, seguido de seu prenome, como em referências:

$$
\begin{aligned}
& \text { ABRAMO, Lívio } \\
& \text { AGUILAR, José Roberto } \\
& \text { AMARAL, Tarsila do } \\
& \text { ARAÚJO, Emanoel }
\end{aligned}
$$

A lista trará os nomes dos artistas em ordem alfabética por sobrenome, com remissivas, quando necessário.

\begin{tabular}{|c|}
\hline LISTA DE TÍTULOS \\
\hline Busca pelo nome da obra: \\
Escolar, $O$ \\
Mulato, $O$ \\
Negra, A \\
Ouro Preto \\
Rio \\
São Paulo
\end{tabular}

\begin{tabular}{|c|c|}
\hline \multicolumn{2}{|c|}{ LISTA DE CRONOLOGIA } \\
\hline Busca por séculos: & $\begin{array}{l}\text { Antes do século XVI } \\
\text { Século XVI } \\
\text { Século XVII } \\
\text { Século XVIII } \\
\text { Século XIX } \\
\text { Século XX } \\
\text { Século XXI }\end{array}$ \\
\hline $\begin{array}{l}\text { A lista trará todos o } \\
\text { século escolhido, em orde } \\
\text { do autor. }\end{array}$ & $\begin{array}{l}\text { artistas que fazem parte do } \\
\text { nalfabética por sobrenome }\end{array}$ \\
\hline
\end{tabular}

A lista trará os títulos das obras em ordem alfabética, desprezando-se os artigos que antecedem o nome.

\section{- Linguagem controlada: do conceito ao termo}

Para representar uma imagem quanto ao seu assunto específico (nesse caso, no item natureza ou forma artística) parece mais adequado utilizar (construir) um tesauro que tem por função definir um termo preferido em relação a outro; termos hierárquicos genéricos e específicos e termos associados associativos. Para este estudo é necessário enfatizar que houve intenção de mostrar uma forma possível de realizar a atividade de construção deste tesauro baseado em redes relacionais de conceitos.

No caso do item Natureza ou Forma Artística, listas não seriam suficientes por ocorrência das diversas possibilidades de pesquisa. Nesse caso a solução foi a de elaborar, para essa categoria, um vocabulário controlado a partir de estudos conceituais dos termos envolvidos. "[...] a Terminologia modeliza o conhecimento como campo nocional; a linguagem documentária, modeliza a informação, para constituir sistemas informacionais" (Lara; Tálamo, 2007, s/p.). Tendo como exemplo a experiência didática aplicada por Lara e Tálamo (2007) em relação ao uso da terminologia na elaboração de redes relacionais de conceitos, a fim de construir produtos documentários, objetiva-se, a título de exemplo, mostrar um ensaio aplicado em relação à NATUREZA OU FORMA ARTíSTICA de uma das obras estudadas, tratando-se do assunto: MODERNISMO.

\section{MODERNISMO}

Ficha terminológica de coleta (relação entre o termo e seus usos) 


\begin{tabular}{|c|c|c|c|c|}
\hline $\begin{array}{c}\text { TERMO } \\
\text { CANDIDATO }\end{array}$ & SINÔNIMO & CONTEXTO & FONTE & DOMÍNIO \\
\hline Modernismo & & $\begin{array}{l}\text { "O Modernismo Brasileiro é um movimento de } \\
\text { amplo espectro cultural, desencadeado tardiamente } \\
\text { nos anos } 20 \text {, nele convergindo elementos das van- } \\
\text { guardas acontecidas na Europa antes da Primeira } \\
\text { Guerra Mundial. Cubismo e Futurismo - assimila- } \\
\text { dos antropofagicamente em fragmentos justapos- } \\
\text { tos e misturados." }\end{array}$ & $\begin{array}{c}\text { MODERNISMO } \\
\text { BRASILEIRO }\end{array}$ & $\begin{array}{c}\text { Artes } \\
\text { Plásticas }\end{array}$ \\
\hline Modernismo & & $\begin{array}{l}\text { "Chama-se genericamente modernismo (ou movi- } \\
\text { mento moderno) o conjunto de movimentos cultu- } \\
\text { rais, escolas e estilos que permearam as artes e o } \\
\text { design da primeira metade do século XX. O movi- } \\
\text { mento moderno baseou-se na idéia de que as for- } \\
\text { mas "tradicionais" das artes plásticas, literatura, } \\
\text { design, organização social e da vida cotidiana tor- } \\
\text { naram-se ultrapassadas, e que fazia-se fundamen- } \\
\text { tal deixá-los de lado e criar no lugar }\end{array}$ & $\begin{array}{l}\text { MODERNISMO } \\
\text { / WIKIPÉDIA }\end{array}$ & $\begin{array}{c}\text { Artes } \\
\text { Plásticas }\end{array}$ \\
\hline Modernismo & & $\begin{array}{l}\text { No Brasil, o termo identifica o movimento desen- } \\
\text { cadeado pela Semana de Arte Moderna de } 1922 . \\
\text { Uma das primeiras exposições de arte moderna no } \\
\text { Brasil é realizada em } 1913 \text { pelo pintor de origem } \\
\text { lituana Lasar Segall. Em 1917, Anita Malfatti faz a } \\
\text { que é considerada de fato a primeira mostra mo- } \\
\text { dernista brasileira. Apesar de não ter exposto na } \\
\text { Semana de 22, Tarsila do Amaral torna-se funda- } \\
\text { mental para o movimento. Sua pintura é baseada } \\
\text { em cores puras e formas definidas. O principal } \\
\text { escultor modernista é Vitor Brecheret." }\end{array}$ & MODERNISMO 5 & $\begin{array}{c}\text { Artes } \\
\text { Plásticas }\end{array}$ \\
\hline
\end{tabular}

Ficha terminológica de síntese

\begin{tabular}{|c|c|c|c|}
\hline CONTEXTO & $\begin{array}{c}\text { CARACTERÍSTICA } \\
1\end{array}$ & $\begin{array}{c}\text { CARACTERÍSTICA } \\
2\end{array}$ & $\begin{array}{c}\text { CARACTERÍSTICA } \\
3\end{array}$ \\
\hline $\begin{array}{l}\text { "O Modernismo Brasileiro é um movimento } \\
\text { de amplo espectro cultural, desencadeado tar- } \\
\text { diamente nos anos } 20 \text {, nele convergindo ele- } \\
\text { mentos das vanguardas acontecidas na Europa } \\
\text { antes da Primeira Guerra Mundial. Cubismo e } \\
\text { Futurismo - assimilados antropofagicamente } \\
\text { em fragmentos justapostos e misturados." }\end{array}$ & $\begin{array}{l}{[\ldots] \text { é um movimento }} \\
\text { de amplo espectro } \\
\text { cultural, desencadea- } \\
\text { do tardiamente nos } \\
\text { anos } 20[\ldots]\end{array}$ & $\begin{array}{l}\text { [...] Cubismo e Futurismo- } \\
\text { assimilados antropofagica- } \\
\text { mente em fragmentos justa- } \\
\text { postos e misturados. }\end{array}$ & \\
\hline
\end{tabular}

3 MODERNISMO BARSILEIRO. In: SITE MODERNISMO. Disponível em: <http://www.mac.usp. br/ projetos/seculoxx/modulo2/ modernismo/index.html >. Acesso em: 22 out. 2007.

${ }^{4}$ MODERNISMO. In: WIKIPÉDIA. Disponível em: < http://pt.wikipedia.org/wiki/Modernismo>. Acesso em: 22 out. 2007.

${ }^{5}$ MODERNISMO. In: TERRA. Disponível em: <http://paginas.terra.com. br/arte/mundoantigo /impressionismo/3.htm>. Acesso em: 22 out. 2007. 


\begin{tabular}{|c|c|c|c|}
\hline CONTEXTO & $\begin{array}{c}\text { CARACTERÍSTICA } \\
1\end{array}$ & $\begin{array}{c}\text { CARACTERÍSTICA } \\
2\end{array}$ & $\begin{array}{c}\text { CARACTERÍSTICA } \\
3\end{array}$ \\
\hline $\begin{array}{l}\text { "Chama-se genericamente modernismo (ou } \\
\text { movimento moderno) o conjunto de movimen- } \\
\text { tos culturais, escolas e estilos que permearam } \\
\text { as artes e o design da primeira metade do sécu- } \\
\text { lo XX. O movimento moderno baseou-se na } \\
\text { idéia de que as formas "tradicionais" das artes } \\
\text { plásticas, literatura, design, organização social } \\
\text { e da vida cotidiana tornaram-se ultrapassadas, } \\
\text { e que fazia-se fundamental deixá-los de lado e } \\
\text { criar no lugar uma nova cultura." }\end{array}$ & $\begin{array}{l}{[\ldots] \text { o conjunto de }} \\
\text { movimentos culturais, } \\
\text { escolas e estilos que } \\
\text { permearam as artes e } \\
\text { o design da primeira } \\
\text { metade do século XX } \\
{[\ldots]}\end{array}$ & $\begin{array}{l}\text { [...] idéia de que as formas } \\
\text { "tradicionais" das artes } \\
\text { plásticas, literatura, design, } \\
\text { organização social e da vida } \\
\text { cotidiana tornaram-se } \\
\text { ultrapassadas }\end{array}$ & $\begin{array}{l}{[\ldots] \text { criação de uma }} \\
\text { nova cultura. }\end{array}$ \\
\hline $\begin{array}{l}\text { No Brasil, o termo identifica o movimento de- } \\
\text { sencadeado pela Semana de Arte Moderna de } \\
\text { 1922. Uma das primeiras exposições de arte } \\
\text { moderna no Brasil é realizada em } 1913 \text { pelo } \\
\text { pintor de origem lituana Lasar Segall. Em 1917, } \\
\text { Anita Malfatti faz a que é considerada de fato a } \\
\text { primeira mostra modernista brasileira. Apesar } \\
\text { de não ter exposto na Semana de 22, Tarsila do } \\
\text { Amaral torna-se fundamental para o movimen- } \\
\text { to. Sua pintura é baseada em cores puras e } \\
\text { formas definidas. O principal }\end{array}$ & $\begin{array}{l}{[\ldots] \text { o movimento de- }} \\
\text { sencadeado pela Se- } \\
\text { mana de Arte Moder- } \\
\text { na de } 1922[\ldots]\end{array}$ & $\begin{array}{l}\text { [...] Uma das primeiras expo- } \\
\text { sições de arte moderna no } \\
\text { Brasil é realizada em } 1913 \\
\text { pelo pintor de origem lituana } \\
\text { Lasar Segall. Em 1917, Anita } \\
\text { Malfatti faz a que é conside- } \\
\text { rada de fato a primeira mos- } \\
\text { tra modernista brasileira. } \\
\text { Apesar de não ter exposto na } \\
\text { Semana de 22, Tarsila do } \\
\text { Amaral torna-se fundamen- } \\
\text { tal para o movimento. Sua } \\
\text { pintura é baseada em cores } \\
\text { puras e formas definidas. } \bigcirc \\
\text { principal escultor modernis- } \\
\text { ta é Vitor Brecheret." }\end{array}$ & \\
\hline \multicolumn{4}{|c|}{$\begin{array}{l}\text { Modernismo: proposta de definição: } \\
\text { O Modernismo é o conjunto de movimentos culturais, escolas e estilos que permearam as artes e o design da primeira } \\
\text { metade do século XX. No Brasil desenvolve-se tardiamente nos anos } 20 \text { desencadeado pela Semana de Arte Moderna de } \\
\text { 1922. Tem por princípio a idéia de que as formas "tradicionais" das artes plásticas, literatura, design, organização social } \\
\text { e da vida cotidiana tornaram-se ultrapassadas. Configura-se como o movimento da criação de uma nova cultura. Alguns } \\
\text { dos grandes expoentes desse movimento foram: Lasar Segall, Anita Malfatti, Tarsila do Amaral, Victor Brecheret, entre } \\
\text { outros. }\end{array}$} \\
\hline
\end{tabular}

Árvore de domínio: dois modos de representação - Primeiro modo de representação

As formas tradicionais das artes plásticas e da vida tornam-se ultrapassadas

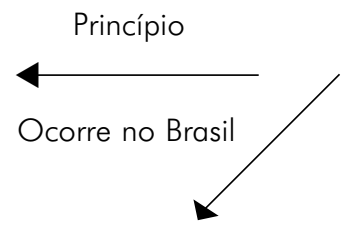

Modernismo

Expressa-se por

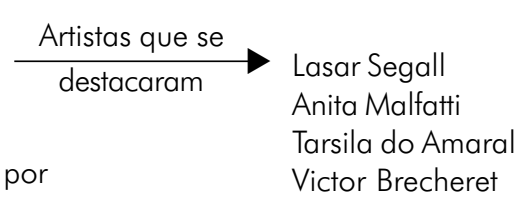

Através da Semana de Arte Moderna

Criação de uma nova cultura 


\section{Segundo modo de representação}

\begin{tabular}{|c|c|c|l|}
\hline Princípio & $\begin{array}{c}\text { Ocorrência } \\
\text { no Brasil }\end{array}$ & $\begin{array}{c}\text { Modo de } \\
\text { Expressão }\end{array}$ & Principais Artistas \\
\hline Artes & Durante e & Criação & Lasar Segall \\
plásticas & após a & de uma & Anita Malfatti \\
ultrapas- & Semana de & nova & Tarsila do Amaral \\
sadas & Arte & cultura & Victgor Brecheret \\
& Moderna & & \\
\hline
\end{tabular}

Reorganizando os termos em categorias

\section{Movimento Artístico}

\section{Princípio}

\section{Modo de expressão}

Criação de uma nova cultura

\section{Ocorrências no Brasil}

Semana de Arte Moderna

\section{Principais Artistas}
Lasar Segall
Anita Malfatti
Tarsila do Amaral

Rede relacional de termos no tesauro

\section{MODERNISMO}

NE É o conjunto de movimentos culturais, escolas e estilos que permearam as artes e o design da primeira metade do século XX, desenvolvendo-se tardiamente no Brasil à partir da Semana de Arte Moderna de 1922. Tem por princípio a idéia de que as formas "tradicionais" das artes plásticas, literatura, design, organização social e da vida cotidiana tornaram-se ultrapassadas. Configura-se como o movimento da criação de uma nova cultura. Alguns dos grandes expoentes desse movimento foram: Lasar Segall, Anita Malfatti, Tarsila do Amaral, Victor Brecheret, entre outros.

TG Movimentos Artísticos

TR Semana de Arte Moderna

TR Lasar Segall

TR Anita Malfatti

TR Tarsila do Amaral

TR Victor Brecheret
As outras duas tipologias de descritores Temáticos descritivos e Temáticos interpretativos - não fazem parte do universo da palavra e sim do universo do discurso. Sendo assim, não há possibilidade de prédeterminar os termos ou expressões utilizadas, já que são expressas por meio de textos (produção textual). A categoria anteriormente trabalhada é da ordem da palavra, por isso é possível pré-determinar seus termos, o contrário do ocorrido com as categorias de descritores Temáticos descritivos e Temáticos interpretativos, que são da ordem do discurso e não possibilitam a elaboração de uma linguagem controlada.

A categoria de descritores Temáticos descritivos descreve e identifica os objetos das imagens tendo sempre como referência o léxico. Ex.: Sol, Lua, Mulher de meia idade, etc.

Em termos da categoria dos descritores Temáticos interpretativos, uma observação importante é que a interpretação, além de discursiva, é também infinita quanto ao seu número e ao seu processo. Por um lado, não há interpretação definitiva nem processo de interpretação que, alguma vez, possa dizer-se verdadeiramente acabado: a série das revelações não está nunca fechada, e toda proposta de interpretação é passível de revisão, integração, aprofundamento, e há sempre alguma nova circunstância que a desmente, ou limita, ou corrige: cada vez que se relê uma obra, o processo de interpretação que se mantinha fechado reabre-se, e tudo é recolocado em questão; mesmo aquilo que se conservou da primeira interpretação é profundamente mudado, acolhido num novo contexto e integrado por novas descobertas (Pareyson, 2001, p. 224).

Nesse sentido, a linguagem que se coloca para efetivar a busca de informação nessas categorias mostrase aberta, ou seja, qualquer expressão de busca pode ser recuperada se foi inserida no momento da indexação, não sendo possível para tais categorias, na medida em que integram a ordem discursiva, um controle terminológico.

Apesar de se concordar que o tesauro é a linguagem documentária mais completa, há que se considerar que o vocabulário controlado mais simples, até as listas nos três primeiros casos, auxilia de forma expressiva a sistematização de conceitos, principalmente se o local no qual se desenvolve a atividade de tratamento da informação carece de recursos básicos de documentação, como a presença de uma 
metodologia específica. A incipiente pesquisa em materiais imagético-pictóricos no Brasil supõe que se inicie o processo com o estudo de uma metodologia que estabeleça alguns procedimentos documentários para que, posteriormente, seja viável aplicar uma linguagem de indexação. Porém, ousa-se sugerir, como material de apoio, a já explicitada sistematização de linguagem que visa a auxiliar a rotina do profissional que se dedica ao trabalho de representação de pinturas, ressalvando as características dos descritores vinculados a esse tipo de material.

\section{BIBLIOGRAFIA}

Colocação das referências utilizadas em todo o processo de tratamento informacional de cada imagem.
Essa bibliografia poderia ajudar em outras pesquisas documentárias que se relacionassem com o mesmo tema.

\section{Planilhas}

As planilhas que seguem têm a função de padronizar as etapas do tratamento da informação imagético-pictórica, evidenciando a possibilidade de aplicação metodológica. É dividida em três partes, sendo a primeira de ordem interna, a segunda dos produtos documentários (resumo) que aparecem para o usuário e a terceira dos produtos documentários que possibilitam a procura pela informação (descritores). 
PLANILHA 1

Funções internas da Instituição

\begin{tabular}{|c|c|}
\hline \multirow{12}{*}{ IMAGEM } & DADOS CATALOGRÁFICOS \\
\hline & AUTORIA \\
\hline & AUTOR: \\
\hline & LOCAL E DATAS * e +: \\
\hline & OBRA \\
\hline & TÍTULO: \\
\hline & ANO DE EXECUÇÃO: \\
\hline & DGM: \\
\hline & DIMENSÕES: \\
\hline & LOCALIZAÇÃO SEDE: \\
\hline & INSCRIÇÕES: \\
\hline & PROCEDÊNCIA: \\
\hline \multicolumn{2}{|l|}{ ANÁLISE DO CONTEÚDO } \\
\hline \multicolumn{2}{|l|}{ DESCRIÇÃO } \\
\hline \multicolumn{2}{|l|}{ IDENTIFICAÇÃO } \\
\hline INTERPRETAÇÃO & \\
\hline
\end{tabular}

\begin{tabular}{|l|}
\hline \multicolumn{1}{|c|}{ DADOS CATALOGRÁFICOS } \\
\hline AUTORIA \\
\hline AUTOR: \\
\hline LOCAL E DATAS $*+e:$ \\
\hline OBRA \\
\hline TÍTULO: \\
\hline ANO DE EXECUÇÃO: \\
\hline DGM: \\
\hline DIMENSÕES: \\
\hline LOCALIZAÇÃO SEDE: \\
\hline INSCRIÇÕES: \\
\hline PROCEDÊNNCIA: \\
\hline
\end{tabular}

Figura 3. Planilha de funções internas da instituição. 
Produtos documentários - $\bigcirc$ que aparece para o usuário após a busca.
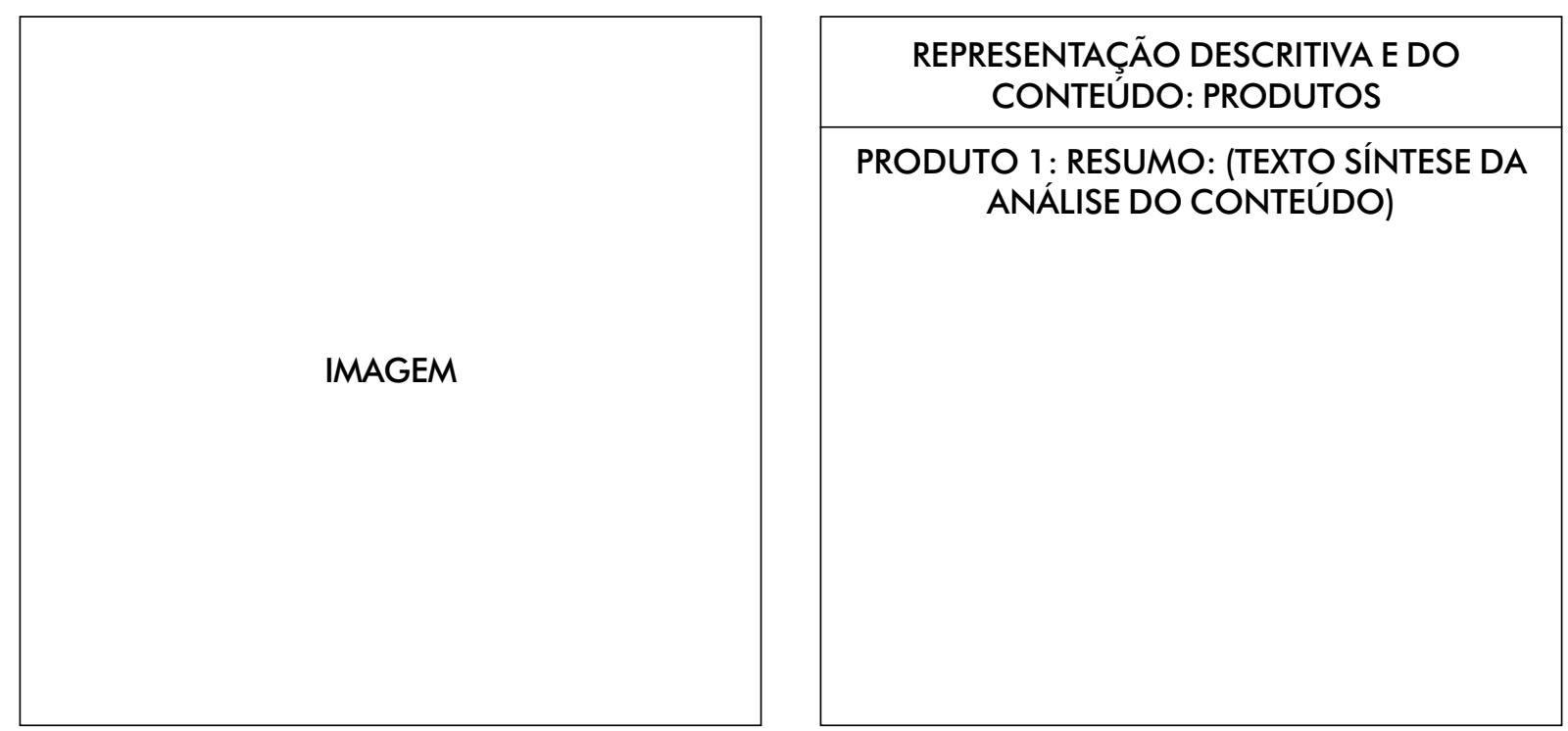

Figura 4. Planilha de produto documentário: exibição para o usuário.

PLANILHA 3

Produtos documentários - Como o usuário pode procurar a informação.

REPRESENTAÇÃO DESCRITIVA E DO CONTEÚDO: PRODUTOS

PRODUTO 2: DESCRITORES

AUTORIA:

TÍTULO:

CRONOLOGIA:

NATUREZA/FORMA ARTÍSTICA:

TEMÁTICOS DESCRITIVOS:

TEMÁTICOS INTERPRETATIVOS:

Figura 5. Planilha de produto documentário: busca da informação. 


\section{CONSIDERAÇÕES FINAIS}

Preocupações com o adequado tratamento informacional de imagens motivaram esta pesquisa a propor, por meio da conversão das metodologias já apresentadas, um modelo adaptado aos museus brasileiros de representação documentária. Assim, as planilhas revelam sua possibilidade de implementação, no intuito de permitir que os usuários contemplem e acessem informações disponíveis sobre cada obra de arte encontrada nos museus. Dessa maneira, acreditase que as imagens são fontes de informação que podem gerar conhecimento e despertar a curiosidade dos visitantes desses locais de conhecimento e memória.

\section{REFERÊNCIAS}

AGUSTÍN LACRUZ, M. del C. Análisis documental de contenido del retrato pictórico: propuesta epistemológica y metodológica aplicada a la obra de Francisco de Goya. Cartagena : 3000 Informática, 2006. 271 p. (Tendencias; 3)

ALVES, M. C.; VALERIO, S. A. Manual para indexação de documentos fotográficos. Rio de Janeiro: Departamento de Processos Técnicos - Biblioteca Nacional, 1998. 41 p.

BUCKLAND, M. K. Descrição e pesquisa: metadados como infraestrutura. Brazilian Journal of Information Science, v. 0, n. 0, p. 315, 2006. Disponível em: <http://www.portalppgci.marília. unesp.br/bjis>. Acesso em: 20 out. 2007.

CUNHA, M. B. da; CAVALCANTI, C. R. de O. Dicionário de Biblioteconomia e Arquivologia. Brasília: Briquet de Lemos, 2008. $451 \mathrm{p}$.

FERREIRA, A. B. de H. Miniaurélio século XXI: o minidicionário da língua portuguesa. 4. ed. rev. e ampl. Rio de Janeiro: Nova Fronteira, $2000.790 \mathrm{p}$.

LARA, M. L. G. de ; TÁLAMO, M. de F. G. M. Uma experiência na interface Lingüística Documentária e Terminologia. Datagramazero: revista de Ciência da Informação, v. 8, n. 5, out./2007.

MANINI, Miriam Paula. Análise documentária de fotografias: um referencial de leitura de imagens fotográficas para fins documentários. 2002. 232 f. Tese (doutorado em Ciências da Comunicação) - Escola de Comunicação e Artes, Universidade de São Paulo, 2002.

PAREYSON, L. Os problemas da estética. 3. ed. São Paulo : Martins Fontes, 2001. 246 p.

RIBEIRO, A. M. de C. M. Catalogação de recursos bibliográficos pelo AACR2R 2002. Brasília : Editora do Autor, 2003.

SMIT, J. W. Análise documentária: a análise da síntese. Brasília: IBICT, 1987. 133 p. 